\section{Revista Brasileira de Administração Científica}

Brazilian Journal of Scientific Administration

Jul a Set $2020-v .11-n .3$
ISSN: 2179-684X

\title{
Profissionalização do serviço público: análise dos concursos públicos para servidores técnico-administrativos dos institutos federais
}

O processo de seleção de profissionais para a ocupação dos cargos públicos necessários ao funcionamento das organizações públicas se constitui como um passo fundamental para a adequada prestação dos serviços ofertados por estas instituições, visto que a atuação de profissionais capacitados constitui uma variável fundamental para que a organização alcance sua missão. Assim, é de suma importância a realização de pesquisas que investiguem se as seleções empregadas pelas instituições estão realmente possibilitando a escolha dos melhores profissionais. Neste sentido, este trabalho objetiva verificar de que forma são realizados os concursos públicos dos Institutos Federais de Educação, Ciência e Tecnologia (IFs) para provimento dos cargos da carreira Técnico-Administrativa em Educação (TAE), quanto às fases de realização e às áreas de conhecimento exigidas nas provas. Para tanto, compararam-se os concursos de IFs de sete estados do Nordeste (Ceará, Maranhão, Paraíba, Pernambuco, Piauí, Rio Grande do Norte e Sergipe) realizados entre os anos 2015 e 2018. Através de uma pesquisa documental, foram identificadas as principais diferenças e semelhanças nos concursos públicos realizados por estas instituições e discutiu-se os possíveis impactos deste cenário. Os resultados apontam que a maioria dos IFs apresenta modelos de seleção de servidores TAE com características similares, o que reforça a ideia de rede de ensino e de melhor fluxo de servidores entre as instituições. No entanto, isso não pode ser considerado um padrão, pois alguns IFs utilizam modelos de seleção destoantes dos principais modelos adotados.

Palavras-chave: Gestão de Pessoas; Políticas e Práticas na Gestão de Pessoas; Setor Público.

\section{Professionalization of public service: analysis of public tenders for technical-administrative servants of federal institutes}

\begin{abstract}
The process of selecting professionals to occupy public positions necessary for the functioning of public organizations is a fundamental step towards the adequate provision of services offered by these institutions, since the performance of trained professionals is a fundamental variable for the organization achieve your mission. Thus, it is extremely important to carry out research that investigates whether the selections employed by the public institutions are really enabling the choice of the best professionals. In this sense, this work aims to verify how public tenders are held by the Federal Institutes of Education, Science and Technology to fill the posts of the Technical-Administrative career in Education (TAE), regarding the stages of realization and the areas knowledge required in the tests. For that, the selections of Federal Institutes from seven states in the Northeast (Ceará, Maranhão, Paraíba, Pernambuco, Piauí, Rio Grande do Norte and Sergipe) were compared between the years 2015 and 2018. Through a documentary research, the main differences and similarities in the public tenders carried out by these institutions and the possible impacts of this scenario were discussed. The results show that most Federal Institutes present models of selection of TAE servers with similar characteristics, which reinforces the idea of a teaching network and a better flow of servers between institutions. However, this cannot be considered a standard, as some Federal Institutes use selection models different from the main models adopted.
\end{abstract}

Keywords: People Management; Policies and Practices in People Management; Public Sector.

Topic: Gestão Pública

Reviewed anonymously in the process of blind peer

Débora Bruna Alves Almeida

Universidade Federal de Campina Grande, Brasil

http://lattes.cnpq.br/4191618321723028

http://orcid.org/0000-0002-9758-3227

debora.almeida@ifce.edu.br

Thales Fabricio da Costa e Silva (iD)

Universidade Federal de Campina Grande, Brasil

http://lattes.cnpq.br/1451673264440003

http://orcid.org/0000-0003-1828-3259

thalespsic@gmail.com

Jacyara Farias Souza

Universidade Federal de Campina Grande, Brasil http://lattes.cnpq.br/9027755945896248

http://orcid.org/0000-0002-4033-2064

jacyfarias@gmail.com
Received: 09/06/2020

Approved: 30/07/2020
Referencing this:

ALMEIDA, D. B. A.; SILVA, T. F. C.; SOUZA, J. F.. Profissionalização do serviço público: análise dos concursos públicos para servidores técnico-administrativos dos institutos federais. Revista Brasileira de Administração Científica, v.11, n.3, p.199-209, 2020. DOI:

http://doi.org/10.6008/CBPC2179-684X.2020.003.0014

DOI: 10.6008/CBPC2179-684X.2020.003.0014 


\section{INTRODUÇÃO}

O processo de profissionalização do serviço público brasileiro, que se caracteriza pela busca de uma Administração Pública mais eficiente, eficaz, baseada em critérios democráticos e meritocráticos, que promova a oferta de serviços públicos de forma a satisfazer as demandas da sociedade e que otimize o funcionamento do aparelho estatal, tem evoluído gradativamente conforme as novas necessidades surgidas no seio social, como também, conforme as diversas mudanças e reformas ocorridas na Administração Pública do Brasil.

A implantação da reforma burocrática, na década de 1930, constituiu-se como uma primeira tentativa de profissionalização do serviço público brasileiro, trazendo consigo os preceitos da Burocracia Weberiana, como a racionalização administrativa e a meritocracia, em oposição ao clientelismo e ao nepotismo, característicos do modelo patrimonialista (CARNEIRO et al., 2013).

O processo de ocupação do serviço público, conforme uma abordagem mais meritocrática, foi fortemente colocado em prática nas décadas que se seguiram, especialmente com a promulgação da Constituição Federal de 1988, sobretudo com a edição da Emenda Constitucional no 19, de 04 de junho de 1998, que instituiu a adoção do concurso público para o ingresso em todo e qualquer cargo ou emprego público de caráter efetivo, bem como estabeleceu a criação do Regime Jurídico Único e de planos de carreira para os servidores da Administração Pública direta, das autarquias e das fundações públicas (CAVALCANTE et al., 2017).

Para que o processo de seleção de profissionais através de concursos públicos atinja seu objetivo de escolher os profissionais mais capacitados para a ocupação de cargos públicos, sua elaboração deve ser muito bem planejada, quanto à forma, objeto e finalidade. Todas as fases e conteúdos programáticos das provas devem estar alinhados às atribuições e especificidades do cargo, a fim de que os aprovados tenham um perfil adequado e possuam o rol de conhecimentos necessários para o desenvolvimento satisfatório das atividades inerentes ao cargo ocupado. Assim, entende-se que o provimento de cargos públicos por servidores mais capacitados, possuidores dos diversos conhecimentos necessários à atuação no seu cargo e no papel de servidor público, é fator crucial para a profissionalização das organizações públicas.

Os Institutos Federais de Educação, Ciência e Tecnologia (IFs), instituições de ensino criadas pela Lei Federal no 11.892, de 29 de dezembro de 2008, vinculam-se ao Ministério da Educação e possuem natureza jurídica de autarquia, provendo a ocupação dos cargos efetivos para as carreiras de Técnico-Administrativo em Educação (TAE) e docente, mediante aprovação em concurso público de provas ou de provas e títulos (BRASIL, 2008).

Compreende-se que o processo de seleção de profissionais para a ocupação dos cargos públicos necessários ao funcionamento pleno dos IFs de todo o país se constitui como um passo fundamental para a adequada prestação dos serviços ofertados por estas instituições, visto que a atuação de profissionais capacitados, que disponham de conhecimentos e habilidades requeridas pelo cargo e, além disso, cientes do seu papel enquanto servidor público, constituem uma variável fundamental para que a instituição alcance 
sua missão. Deste modo, é de suma importância a realização de pesquisas que investiguem se as formas de seleção empregadas pelas instituições estão realmente possibilitando a escolha dos melhores profissionais.

Constata-se a escassez de trabalhos com objeto de estudo similar a este - a análise dos editais de concursos com foco nos conteúdos programáticos cobrados e conhecimentos e habilidades exigidos para o exercício de determinados cargos - e, conforme indicam Fontainha et al. (2014), são estudos fundamentais para a compreensão do modelo de seleção que vem sendo utilizado, focado na quantidade de conhecimentos acumulados pelos candidatos.

Deste modo, o objetivo desta pesquisa é verificar de que forma são realizados os concursos públicos dos IFs para provimento dos cargos da carreira TAE, quanto ao número e tipos de fases realizadas e também em relação às áreas de conhecimento exigidas nas provas, comparando os modelos de seleção adotados pelos IFs de sete estados do Nordeste: Ceará, Maranhão, Paraíba, Pernambuco, Piauí, Rio Grande do Norte e Sergipe.

\section{REVISÃO TEÓRICA}

\section{Evolução dos modelos de Administração Pública no Brasil}

A Administração Pública brasileira passou por diversas reformas, visando mais eficiência. Acompanhando as tendências internacionais, pode-se dizer que a Administração Pública no Brasil passou por três grandes etapas e modelos de administração: a patrimonialista, a burocrática e a gerencial. 0 modelo de administração patrimonialista, que vigorou no país desde os anos de 1500 a 1930, constitui-se como uma forma de administrar típica dos governos monárquicos, na qual o Estado se torna uma extensão do poder do soberano. Este modelo possuía como principais características o nepotismo - visto que os cargos públicos eram ocupados de acordo com o grau de parentesco com os nobres e demais integrantes do governo, não havendo assim critérios baseados na meritocracia - e a corrupção, visto que não havia distinção entre o capital particular e o patrimônio público (TORRES, 2004; REK, 2014).

Somente a partir de 1930, durante o primeiro governo do presidente Getúlio Vargas, é que houve a tentativa de transformação do serviço público. Seguindo uma influência norte-americana, buscou-se a implantação de uma administração baseada nos preceitos da administração racional-legal: o modelo burocrático descrito por Max Weber (RIBEIRO et al., 2013). A tentativa de implantação do modelo burocrático teve como principal objetivo livrar a Administração Pública dos estigmas deixados pelo patrimonialismo, corrupção e nepotismo, para passar a adotar um sistema de administração pautado no profissionalismo e na meritocracia.

Apesar dos primeiros avanços rumo à uma Administração Pública mais profissionalizada, realizados principalmente pelo Departamento de Administração do Serviço Público (Dasp), criado em 1938, que instituiu normas para o recrutamento e a seleção de pessoal para a ocupação dos cargos públicos, através da adoção obrigatória de concursos públicos, por meio de critérios baseados em mérito, constatou-se que o modelo burocrático não foi capaz de sanar as mazelas deixadas pelo patrimonialismo. 
Conforme o Ministério da Administração Federal e da Reforma do Estado (MARE, 1995), com o aumento dos serviços públicos prestados à sociedade, notou-se que a administração burocrática era ineficiente. Deste modo, surge o modelo de administração pública gerencial, como forma de resposta aos efeitos negativos da burocracia. Este possui o foco no interesse público, visando entregar ao cidadão serviços públicos de qualidade e com mais eficiência.

Pode-se dizer que a primeira tentativa de implantação da Administração Pública gerencial no Brasil deu-se com o Decreto-Lei no 200/1967, que, numa tentativa de superar a rigidez burocrática, teve como principal medida a descentralização de atividades de produção de bens e serviços para a administração indireta (BRESSER-PEREIRA, 1996). A segunda tentativa de implantação da administração gerencial ocorreu em 1995, através da criação do MARE, com a introdução da Emenda Constitucional que trata do Plano Diretor de Reforma do Estado, a Emenda Constitucional no 19, de 04 de junho 1998. Dentre as principais modificações introduzidas pela EC no 19/1998, Carvalho (2011) destaca os seguintes aspectos: a mudança na estabilidade dos servidores públicos, com a incorporação da possibilidade de demissão por insuficiência de desempenho; o aumento do período do estágio probatório, que passou de dois para três anos; e a extinção da isonomia de vencimentos entre os servidores dos três poderes.

Atualmente, muito se comenta sobre a necessidade de mudanças na Administração Pública, a fim de que essa se torne mais profissionalizada. Os preceitos mais modernos acerca do funcionamento da Administração Pública se aproximam bastante do idealizado na reforma gerencial: modernização dos procedimentos, uso de tecnologia da informação, redução de procedimentos burocráticos para uma maior eficiência e economicidade de tempo e recursos, dentre outros.

\section{Considerações acerca dos concursos públicos}

O instituto do concurso público como forma de seleção e recrutamento para a ocupação de cargos em instituições públicas teve seus primórdios na França, durante o império de Napoleão Bonaparte, em meados do século XVIII, visto que seu Código Civil trazia dispositivos que influenciaram a criação do princípio da isonomia e de outras legislações pertinentes ao tema (CANOTILHO, 1998).

Nota-se que o concurso público, apesar de poder conter vícios que deixem à prova a sua eficácia, constitui-se ainda como o melhor mecanismo de seleção, quando comparado a outros já utilizados para essas situações no decorrer da história, tais como: sorteio, sistema de compra e venda de cargos públicos, arrendamento, sucessão hereditária, sistema de livre nomeação absoluta ou relativa e eleição. Isto porque o concurso realizado através de critérios meritocráticos e pautado no princípio da isonomia, dentre outros princípios que the forem correlatos, tem como uma de suas principais vantagens afastar aqueles indivíduos que não atendem às exigências mínimas para o exercício da função pública (CARVALHO, 2010).

No Brasil, os primórdios do instituto do concurso público remontam à Constituição do Império, de 1824, que dispõe em seu art. 179, inciso XIV, que todo cidadão poderá ser admitido aos cargos públicos civis, políticos e militares, sem outra diferença, senão seus talentos e virtudes, garantindo o direito à liberdade de competição e acesso aos cargos, muito embora a vagueza dos critérios "talentos e virtudes" continuassem a 
possibilitar a discricionariedade e o uso de critérios meramente políticos na escolha dos candidatos (SOUSA, 2000). Foi somente na Constituição de 1967 que ficou estabelecida a obrigatoriedade do concurso público como seleção para todos os cargos, exceto os comissionados; além disso, foi retirada a possibilidade de concursos no qual o único requisito era a análise de títulos.

A despeito dos dispositivos constitucionais, legais e regulamentares já existentes acerca da questão, nota-se que ainda há a indispensabilidade de uma lei geral que discipline o instrumento em âmbito federal e que possa servir de subsídio para iniciativas de mesma natureza do âmbito dos estados e municípios, visto que mesmo com a existência dos dispositivos legais citados, há lacunas passíveis de normatização para que este processo alcance eficiência, eficácia e efetividade necessárias à condução da profissionalização do serviço público e da função pública. Desta forma, corroborando com o entendimento de outros autores (RODIGHERI, 2016; SOUSA, 2011), entende-se como imprescindível a aprovação de um instrumento que trate da questão de forma mais profunda.

Enquanto o tema não é melhor regulamentado, fica a cargo das instituições organizadoras estabelecerem as normas que regerão os concursos, dispostas claramente em edital, em consonância com o texto constitucional, com as leis, com o decreto, bem como com os princípios relacionados.

Observa-se que o instituto do concurso público está estreitamente ligado à questão da profissionalização da função pública e esta, por sua vez, como comenta Bacellar Filho (2003), encontra-se relacionada aos postulados constitucionais. Para este autor, a Administração Pública legitima a sua atuação quando age em conformidade com o interesse público e, sendo a profissionalização da função pública instrumento de melhoria da eficiência, eficácia e efetividade dos serviços prestados pelo Estado, a mesma também configura-se como instrumento de legitimação da Administração Pública diante da sociedade brasileira, pois visa assegurar a obediência ao princípio da igualdade na escolha de seus agentes e cumprir o princípio da eficiência ao atender aos interesses da coletividade, através da busca por uma Administração mais capacitada.

Um dos objetivos precípuos do concurso público é a escolha dos melhores profissionais ao exercício de determinado cargo ou emprego público, visto que, em tese, os candidatos selecionados serão aqueles que se encontram mais bem preparados, qualificados e habilitados para o exercício das atividades inerentes ao serviço público. No entanto, como bem ressalta Silveira (2009), por conta de ineficiências presentes tanto neste processo como em outros processos da Administração, devido à ocorrência de falhas, sobre as quais a doutrina e a jurisprudência se debruçam constantemente em seus apontamentos, nem sempre a escolha dos melhores candidatos corresponde ao provimento de bons servidores públicos. Ainda assim, não se pode negar a relevância do concurso público como instrumento preliminar de aferição de mérito e competência dos candidatos a servidores públicos que, quando bem executado, constitui-se como ferramenta inicial de profissionalização do serviço público e da função pública.

Isto posto, compreendendo-se a importante relação do concurso público com a profissionalização da função pública e, por conseguinte, do serviço público, observa-se a imprescindibilidade do aperfeiçoamento desta ferramenta, o que será possibilitado mediante a sua melhor regulamentação, padronização e 
objetivação.

\section{METODOLOGIA}

Esta pesquisa se classifica, quanto aos seus objetivos, como exploratória, pois visa proporcionar maior familiaridade com o objeto de estudo. Para Gil (2002), esse tipo de pesquisa tem um planejamento flexível, com vista à consideração dos mais diversos aspectos que se relacionam com o objeto de estudo, envolvendo, na maioria dos casos, pesquisa bibliográfica ou estudo de caso.

No que tange às técnicas empregadas, esta pesquisa se configura como bibliográfica e documental. Para Gil (2017), a pesquisa documental se constitui da análise de documentos que ainda não passaram por tratamento analítico. Chamadas também de fontes primárias de informação, estes documentos podem ser jornais, fotos, filmes, documentos legais, atos jurídicos, dentre outros. $\mathrm{O}$ autor ressalta que este tipo de pesquisa exige maior dedicação do pesquisador, maior atenção aos detalhes para que haja um melhor aproveitamento das diversas informações contidas nos documentos. Neste estudo, os documentos analisados foram os editais dos concursos públicos de IFs da região Nordeste e a legislação correlata ao tema em estudo.

Realizou-se a comparação da forma de seleção utilizada, quanto às fases/etapas, tipos de provas e áreas de conhecimento exigidas, dos modelos utilizados por IFs localizados na região Nordeste: Instituto Federal do Ceará (IFCE), Instituto Federal do Maranhão (IFMA), Instituto Federal da Paraíba (IFPB), Instituto Federal de Pernambuco (IFPE), Instituto Federal do Piauí (IFPI), Instituto Federal do Rio Grande do Norte (IFRN) e Instituto Federal de Sergipe (IFS). Isto se deu por meio da análise dos últimos editais publicados por estes IFs, até novembro de 2018, para seleção de cargos da carreira TAE de nível E (cuja exigência de ingresso é a formação de nível superior) e nível $D$ (que exige formação de nível médio).

Os editais foram retirados dos sites institucionais dos IFs envolvidos no estudo e escolhidos conforme a utilização de dois critérios: deveriam ser os editais publicados mais recentemente e deveriam ter na lista de cargos a serem preenchidos no mínimo dois cargos diferentes para cada carreira analisada.

Foram identificados nos editais quantas e quais fases de provas estavam presentes (provas escritas e provas práticas), se as provas escritas eram objetivas e/ou discursivas e quais áreas de conhecimentos eram exigidas no conteúdo programático.

Foram utilizados os Editais: no 11/GR-IFCE/2016, de 29 de agosto de 2016; no 12/GR-IFCE/2016, de 29 de agosto de 2016; nº2 - IFMA, de 16 de outubro de 2018; no 63/2015 - IFPB, de 04 de maio de 2015; no. 124 - IFPE, de 29 de agosto de 2016; no 79/2016 - IFPI, de 29 de agosto de 2016; no 19/2016REITORIA/IFRN, de 24 de agosto de 2016; no 21/2016-REITORIA/IFRN, de 25 de agosto de 2016; PROGEP/REITORIA/IFS no 13, de 30 de agosto de 2016.

\section{RESULTADOS E DISCUSSÃO}

Ao analisar os editais quanto às fases e tipos de provas para os cargos TAE de nível E, observou-se que impera o caráter objetivo, visto que todos os IFs discriminaram em seus editais a realização de provas 
escritas totalmente objetivas para estes cargos. Percebeu-se também paridade entre os conteúdos programáticos determinados para os diferentes cargos de cada edital, sendo que os conteúdos das áreas de conhecimentos gerais foram exigidos para todos os cargos previstos em cada edital. Assim, aponta-se que os concursos para seleção de TAE de nível E se constituem majoritariamente de uma única fase que consiste na aplicação de uma prova escrita, de caráter objetivo, classificatória e eliminatória. A única exceção encontrada foi no edital do IFS que, além da prova escrita, realiza também uma prova prática para o cargo de Regente. A Figura 1 aponta quais áreas de conhecimento são abordadas nestas provas escritas.

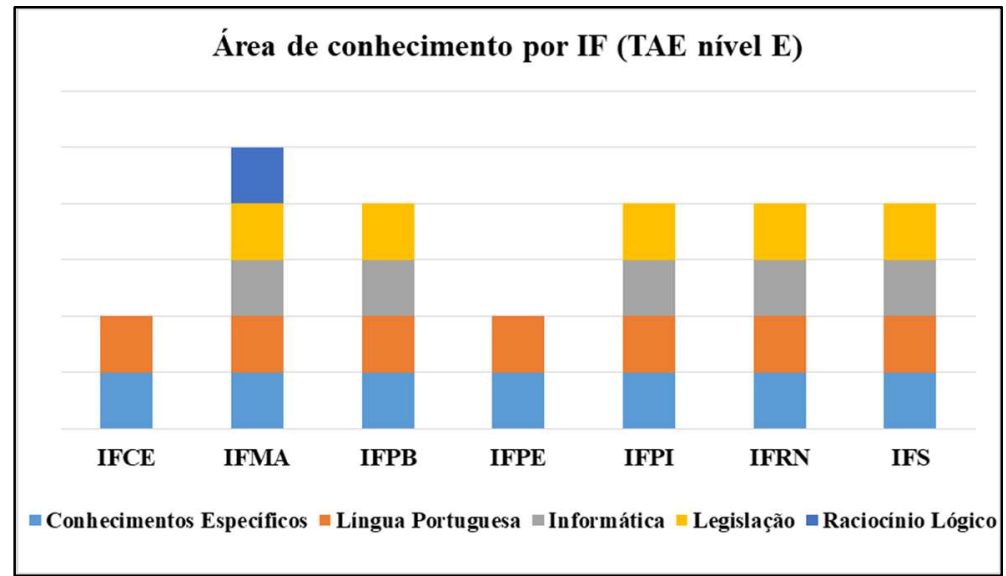

Figura 1: Áreas de conhecimento abordadas nos conteúdos programáticos das provas escritas para seleção de TAEs de nível superior dos IFs.

No concurso para TAE de nível superior, o modelo adotado pelo IFCE se assemelha ao adotado pelo IFPE, visto que ambos exigem apenas os conhecimentos específicos da área de formação ligada a cada cargo e conhecimentos de língua portuguesa. Enquanto isso, os demais IFs abordam, além dos conhecimentos dessas duas áreas, conhecimentos relacionados à informática e à legislação do serviço público. O IFMA foi o único a colocar conhecimentos relativos ao raciocínio lógico. O IFPI traz conteúdos inerentes aos Fundamentos da Administração Pública, no entanto, para esse conjunto de conteúdos também foi dado o título de legislação, para uma melhor elaboração da Figura 1, visto que alguns dos assuntos nele abordados são correspondentes aos assuntos que os demais IFs listaram nos conjuntos intitulados como legislação, assim foram equiparados.

No que se refere ao modelo de seleção adotado pelos IFs para a escolha de servidores TAE de nível D, observou-se em todos os editais a aplicação de uma fase escrita composta de provas objetivas. Apenas o IFCE previu em seu edital a aplicação de provas discursivas, aplicadas em conjunto com as provas objetivas para os cargos de técnico de laboratório/área.

Quanto às áreas de conhecimento determinadas para os cargos de nível médio, percebeu-se que cada edital exigiu as mesmas áreas de conhecimentos gerais para todos os cargos, exceto o do IFCE. Neste Instituto, as áreas de conhecimento exigidas para o cargo de Assistente em Administração superam as impostas para os demais cargos de nível médio, pois continha, além das duas áreas de conhecimento exigidas para os demais cargos, questões referentes a noções de informática.

Ao realizar o levantamento de quais áreas de conhecimento são previstas para os cargos de nível 
médio, notou-se que praticamente não diferem das abordadas para os cargos de nível superior. As únicas diferenças surgidas foram a exclusão dos conteúdos atinentes ao raciocínio lógico e inclusão de questões de matemática no edital do IFMA e, ainda, a adição da matemática no edital do IFPE.

Ainda verificando os editais quanto ao modelo adotado para seleção de TAE de nível $D$, foi possível constatar que, para alguns cargos, tem-se, além da prova escrita, uma prova prática, como é o caso do edital do IFMA, que especifica uma prova prática para o cargo de Tradutor e Intérprete de Linguagem de Sinais (LIBRAS), do IFPE, que tem prova prática para os cargos de técnico de laboratório/área, e do IFRN, que possui prova prática para ambos os cargos citados. Já os editais do IFPI e do IFPB, que também continham vagas para o cargo de Tradutor e Intérprete de Linguagem de Sinais (LIBRAS), não previram prova prática para este cargo. Assim como o IFCE, o IFMA, o IFPI, o IFS e o IFPB também não exigiram prova prática para os cargos de técnico de laboratório/área. Deste modo, vê-se que, em geral, na seleção de TAE há uma fase composta por uma prova escrita, podendo haver, em determinadas situações, uma segunda fase, que consiste de uma prova prática aplicada para alguns cargos específicos, como os dos exemplos citados.

Foram observadas diversas semelhanças nos temas que compõem os roteiros de estudo, sendo que as instituições compartilham da cobrança de alguns assuntos. Nos roteiros previstos para os TAE de nível E, por exemplo, a Lei no 8.112/90 está presente entre o conteúdo de legislação das cinco instituições que abordam essa área de conhecimento. Também são observadas algumas disparidades, visto que há assuntos elencados de forma exclusiva por algum IF, como redação oficial, que é abordada apenas no edital do IFCE, ou a Lei no 8.666/93, exigida somente no edital do IFPI. Entretanto, ainda que as instituições não tenham uma linearidade quanto aos conteúdos abordados para cada área de conhecimento, o fato é que a exigência de determinadas áreas de conhecimento na maioria dos editais sugere que estas caminham para um consenso quanto ao perfil desejado para os seus profissionais.

A partir da análise dos editais, é possível notar que as instituições esperam que seus servidores TAE sejam os mais eficientes quanto a sua área de atuação específica, mas que também possuam um rol de conhecimentos em outras áreas, consideradas relevantes para a execução do serviço público. Via de regra, espera-se que estes detenham instrução quanto ao domínio da língua portuguesa, possuam noções de informática e conheçam a legislação que rege as suas atribuições.

O conhecimento da língua portuguesa é considerado essencial para determinadas profissões, principalmente àquelas em que o profissional lida com atendimento ao cliente/cidadão, tanto da forma escrita, como da oral. Araújo et al. (2014) pesquisaram sobre o domínio da língua portuguesa como fator de inclusão/exclusão de candidatos a vagas de emprego em empresas privadas e perceberam a língua como fator determinante de inclusão, o que permite ao trabalhador o acesso ao cargo, com o fim de contribuir essencialmente para o bom funcionamento organizacional e melhores resultados produtivos. Barbosa (2018), comentando sobre a importância do conhecimento da língua portuguesa no setor público e sobre os principais erros cometidos pelos servidores, cita que o servidor público representa os interesses da máquina administrativa, logo, se esse profissional usar um Português inadequado, ele não estará somente se autodepreciando, mas comprometendo também a eficiência que se espera da Administração Pública. Diante 
do exposto, nota-se que o uso correto da língua portuguesa, seja na sua forma falada ou escrita ou ainda no processo de interpretação e compreensão na comunicação, é de grande valia para os profissionais que atuam na área pública.

No que concerne à aplicação de provas com conteúdo voltado para o conhecimento da informática ou tecnologia da informação, identificam-se, através de observação das rotinas e atividades realizadas pelos servidores que laboram nos IFs, situações que podem subsidiar tal fato. É notório que, no mundo atual, as organizações fazem uso de diversos sistemas informatizados, dentre outras ferramentas tecnológicas advindas da informatização. Os processos auxiliados por essas tecnologias são os mais diversos. Nos IFs, por exemplo, os servidores lidam diariamente com diversos sistemas como: o Comprasnet-SIASG, no qual são realizados os processos relacionados às aquisições; o Sistema de Gestão de Pessoas (SIGEPE); o Sistema Único da Administração Pública (SUAP), que auxilia na gestão patrimonial, dentre outras funcionalidades; o Sistema Eletrônico de Informações (Sei), pelo qual tramitam os mais diversos processos administrativos da instituição, dentre outros sistemas. Além destas, os servidores também utilizam ferramentas mais básicas da informática, como editores de texto, planilhas eletrônicas e e-mail. Posto isto, é possível perceber como é relevante para o pleno funcionamento da instituição que os servidores detenham noções de informática e possuam uma boa interação com as ferramentas advindas desta.

A cobrança de conhecimentos relacionados à legislação específica do serviço público, pode ser justificada pela relevância de que o futuro servidor entenda os conceitos, princípios, regras, normas, dentre outras particularidades peculiares à Administração Pública. O serviço público diferencia-se do privado sob diferentes aspectos, mas principalmente pela sua missão, pela função social que origina a sua existência. Enquanto a empresa privada tem como objetivo precípuo a venda de produtos e ou serviços para a obtenção de lucro, uma instituição pública tem como missão norteadora o dever de servir à sociedade com a responsabilidade de proporcionar o bem da coletividade com a prestação de serviço ao público. Deste modo, o servidor deve exercer seu cargo pondo em prática todas as habilidades e conhecimentos que possui pertinentes à sua área de atuação, mas lembrando que é um servidor público e, como tal, deve pautar sua vida profissional conforme preceituam as normas, as leis, os princípios e valores que regem a Administração Pública.

Observando-se os apontamentos realizados acerca das principais diferenças e similaridades existentes entre os editais de concursos para a seleção de servidores TAEs dos IFs, nota-se que estes são semelhantes principalmente quanto à sua forma, visto que, via de regra, são realizados através de uma única fase que consiste da aplicação de uma prova escrita objetiva de múltipla escolha, ressalvadas as exceções em que foram utilizadas também uma segunda fase com a aplicação de prova prática. Também se verificou similaridades quanto às áreas de conhecimentos gerais abordadas nos conteúdos programáticos, pois a maioria dos editais analisados trazia em seus conteúdos a cobrança das mesmas áreas de conhecimentos gerais, sendo que apenas dois dos sete IFs que tiveram seus editais analisados se desviaram do perfil encontrado.

Apesar das similaridades encontradas, de modo geral não é possível afirmar a existência de um 
padrão nos concursos dos IFs. É notório que os Institutos Federais que integram a Rede Federal de Educação Profissional, Científica e Tecnológica (RFEPCT) possuem autonomia para realizar seus concursos da maneira que melhor atenda às necessidades que o serviço público exigir, com os tipos de provas e conteúdos programáticos definidos conforme seus próprios critérios. No entanto, a existência de um padrão, principalmente no que se refere aos tipos de provas e às áreas de conhecimentos exigidas, reforçaria a noção de rede.

Além disso, nota-se que o trânsito de candidatos aprovados e de servidores entre as instituições é prática comum nos IFs, especialmente quando se localizam em uma mesma região político-administrativa do País, o que ocorre por meio do aproveitamento de candidatos aprovados de uma instituição para outra e por meio de processos de redistribuição. Assim, a redução das discrepâncias nestes concursos melhoraria este trânsito, visto que os candidatos ou servidores advindos de outras instituições não teriam perfil profissional muito diferente dos admitidos em concursos próprios da instituição destino.

\section{CONCLUSÕES}

A partir da análise dos editais, constataram-se as principais semelhanças e diferenças entre os concursos de sete IFs do Nordeste. As semelhanças encontradas nos modelos de seleção aproximam as instituições reforçando a ideia de que fazem parte de uma rede de ensino, bem como possibilitam uma melhor existência de fluxo de candidatos e servidores entre as instituições, através de processos de aproveitamento de candidatos aprovados e de processos de redistribuição de servidores.

A principal diferença encontrada nos concursos para seleção de TAE foi quanto às áreas de conhecimento das provas escritas, visto que uma minoria exige somente os conhecimentos da área específica do cargo e conhecimentos de português, enquanto a maioria exige, além das citadas, outras áreas, como informática e legislação do serviço público, principalmente. Ao identificar as principais áreas de conhecimento exigidas, foi possível observar uma tendência na construção de um determinado perfil profissional para os servidores TAE.

O fato de determinado Instituto Federal se distanciar do modelo adotado pela maioria dos IFs da região Nordeste, quanto ao conteúdo das provas escritas para a seleção de servidores TAE, não quer dizer que o mesmo possua um modelo errado ou insatisfatório, enquanto os demais possuem um modelo correto ou ideal, apenas deixa margem para uma reflexão: se o modelo atual adotado pelas instituições possibilita o ingresso de servidores realmente capacitados para lidar com as diversas situações que lhes são impostas em seu cotidiano laboral no serviço público. Vale ressaltar que a exigência excessiva de conteúdos que não estejam relacionados às atividades do cargo, tornam o instrumento de seleção deficitário, no entanto, a não exigência de conteúdos relacionados às atividades correlatas ao trabalho dos servidores provoca o mesmo efeito. Assim, cabe às instituições encontrar o meio para que não pequem pelo excesso, nem pela falta.

Espera-se que esta pesquisa possa contribuir com trabalhos futuros que tratem do tema profissionalização do serviço público, sob o aspecto aqui abordado: seleção de servidores. Por fim, constatase que o concurso público bem realizado é o passo inicial para o processo de profissionalização do serviço 
público e da função pública, devendo ser seguido de outros instrumentos que promovam o desenvolvimento contínuo dos servidores na carreira, como a capacitação profissional.

\section{REFERÊNCIAS}

ARAÚJO, E. M. E.; DIAS, I. S.. O domínio da norma culta da língua portuguesa como determinante de inclusão/exclusão no mundo do trabalho. Revista de Políticas Públicas, São Luís, v.18, n.1, p.255-268, 2014. DOI: http://dx.doi.org/10.18764/2178-2865.v18n1p255-268

BACELLAR FILHO, R. F.. Profissionalização da função pública: a experiência brasileira. Revista Direito Administrativo. Rio de Janeiro, v.232, p.1-9, 2003. DOI: http://dx.doi.org/10.12660/rda.v232.2003.45681

BARBOSA, C.. A importância do domínio da língua portuguesa para os servidores. Folha Dirigida, 2018.

BRASIL. Lei n. 11.892/08. Institui a Rede Federal de Educação Profissional, Científica e Tecnológica, cria os Institutos Federais de Educação, Ciência e Tecnologia, e dá outras providências. Brasília: DOU, 2008.

BRESSER-PEREIRA, L. C.. Crise Econômica e Reforma do Estado no Brasil. 34 ed. São Paulo: 1996.

CANOTILHO, J. J. G.. Direito constitucional e teoria da constituição. 3 ed. Coimbra, 1998.

CARNEIRO, R.; MENICUCCI, T. M. G.. Gestão pública no século XXI: as reformas pendentes. In: FOC. Fundação Oswaldo Cruz. A saúde no Brasil em 2030: prospeç̧ão estratégica do sistema de saúde brasileiro: desenvolvimento, Estado e políticas de saúde. Rio de Janeiro: Fiocruz, 2013. p.135-194.

CARVALHO, E.. O aparelho administrativo brasileiro: sua gestão e seus servidores: do período colonial a 1930. In: CARDOSO JUNIOR, J. C.. Burocracia e ocupação no setor público brasileiro. Brasília: Ipea, 2011.

CARVALHO, R. M. U.. Aspectos Relevantes do Concurso Público. Revista do Tribunal de Contas do Estado de Minas Gerais, v.28, p.101-148, 2010.

CAVALCANTE, P.; CARVALHO, P.. Profissionalização da burocracia federal brasileira (1995-2014): avanços e dilemas. Revista de Administração Pública, Rio de Janeiro, v.51, n.1, p.1-26, 2017. DOI: https://doi.org/10.1590/0034$\underline{7612144002}$
FONTAINHA, F. C.; GERALDO, P. H. B.; VERONESE, A.; ALVES, C. S.; FIGUEIREDO, B. H.; WALDBURGER, J.. Processos seletivos para a contratação de servidores públicos: Brasil, o país dos concursos? Relatório de pesquisa. Rio de Janeiro: Direito Rio, 2014.

GIL, A. C.. Como elaborar projetos de pesquisa. 4. ed. São Paulo: Atlas, 2002.

GIL, A. C.. Como elaborar projetos de pesquisa. 6 ed. São Paulo: Atlas, 2017.

MARE. Ministério da Administração Federal e Reforma do Estado. Plano Diretor da Reforma do Aparelho do Estado Brasília: IN, 1995.

REK, M.. Os modelos de Administração Pública e reflexos à qualidade na gestão administrativa Brasileira. Revista Âmbito Jurídico, 2014.

RIBEIRO, L. M. P; PEREIRA, J. R.; BENEDICTO, G. C.. As Reformas da Administração Pública Brasileira: Uma Contextualização do seu Cenário, dos Entraves e das Novas Perspectivas. In: ENCONTRO DA ANPAD, 37. Anais. Rio de Janeiro: ANPAD, 2013.

RODIGHERI, S.. Concurso público para docentes do magistério superior na Universidade Federal da Grande Dourados: operacionalização do processo de 2009 a 2015. Dissertação (Mestrado Profissional em Administração Pública) - Universidade Federal da Grande Dourados, Mato Grosso do Sul, 2016.

SILVEIRA, R. D.. Profissionalização da função pública. Belo Horizonte: Fórum, 2009.

SOUSA, A. R.. O processo administrativo do concurso público. Dissertação (Mestrado em Direito) - Universidade Federal de Uberlândia, Uberlândia, 2011.

SOUSA, E.. Concurso Público Doutrina e Jurisprudência. Belo Horizonte: Del Rey, 2000.

TORRES, M. D. F.. Estado, Democracia e Administração Pública no Brasil. FGV, 2004.

A CBPC - Companhia Brasileira de Produção Científica (CNPJ: 11.221.422/0001-03) detém os direitos materiais desta publicação. Os direitos referem-se à publicação do trabalho em qualquer parte do mundo, incluindo os direitos às renovações, expansões e disseminações da contribuição, bem como outros direitos subsidiários. Todos os trabalhos publicados eletronicamente poderão posteriormente ser publicados em coletâneas impressas sob coordenação da Sustenere Publishing, da Companhia Brasileira de Produção Científica e seus parceiros autorizados. Os (as) autores (as) preservam os direitos autorais, mas não têm permissão para a publicação da contribuição em outro meio, impresso ou digital, em português ou em tradução. 